\title{
LA PARADOJAL EUFORIA PRIVATIZADORA Apuntes SObre la reforma del Estado en la Argentina
}

\author{
Mabel C. Thwaites Rey (*) / José Ernesto Castillo (**)
}

\section{LOS MARCOS ESTRUCTURALES DE LA REFORMA ESTATAL}

\section{LA REFORMA DEL ESTADO COMO PROCESO GLOBAL}

Desde la asunción del Presidente Carlos Menem en julio de 1989, la Argentina vive una singular paradoja: el partido justicialista gobernante, que históricamente hizo del fortalecimiento del papel del estado como garantía de la justicia social su razón de ser como entidad política, ha emprendido la más audaz cruzada antiestatista y privatizadora conocida en el país. Este cambio, que ha producido un verdadero cimbronazo en la sociedad argentina en general, y particularmente en las estructuras partidarias del peronismo, puede entenderse, mas allá de sus protagonistas concretos, como la coronación de profundas transformaciones estructurales económicas, sociales, políticas e ideológicas- en la sociedad argentina desde mediados de la década de los 70. De esta forma, la deslegitimación explícita de la intervención estatal, característica del discurso y la práctica actualmente dominantes, no puede ser atribuida, exclusivamente, a la voluntad política de un jefe de estado o de un gobierno, más allá de la responsabilidad que a éstos les compete, sino que remite a significativas modificaciones en la lógica de funcionamiento de "lo público", a la par que encuentra una multiplicidad de causas externas e internas que complejizan el fenómeno (THWAITES REY-LOPEZ, 1990b). De ahí que la cuestión de la "reforma del Estado" no tenga un sentido unívoco ni admita explicaciones lineales, si el objetivo consiste en conocer los procesos de fondo en que se sustenta, más allá de los datos y cronologías inmediatos.

Una de las primeras cuestiones a tener en cuenta al analizar la crisis argentina es ubicarla en el contexto internacional, donde se van a entrecruzar perversamente fenómenos como la reconversión tecnológica con la lógica del ajuste producto de la deuda externa. Todo esto estará además teñido por las dificultades propias de la transición democrática. Parecería, entonces, necesario algún tipo de pauta teórica ordenadora de la multiplicidad factual.

\section{EL ESTADO CAPITALISTA PERIFERICO}

Entendemos que, aunque las leyes de la acumulación del capital se expresan en un plano mundial, llegan a los estados-nación mediatizadas por el Comercio Internacional (SALAMA-MATHIAS, 1986). Por lo tanto solo será válido hablar de que en la Argentina la crisis es producto de las disfuncionalidades de la regulación fordista para la valorización del capital si nos remitimos a la disputa por la rejerarquización dinámica de la economía mundial. Disputa a la que no es ajena, obviamente, la problemática financiera de la deuda, pero tampoco la autonomía relativa de los países para salir de ella mejor situados en la mencionada rejerarquización.

Ahora bien, el estado capitalista tiene dos funciones básicamente contradictorias. Por una parte debe asegurar las condiciones que hagan posible la acumulación y reproducción del capital, lo que lo lleva a adoptar las medidas coercitivas necesarias para que las clases subalternas se acomoden -disciplinen- a la lógica del capital. Por otra parte, debe legitimar su dominación para hacerla estable, recurriendo a una serie de mecanismos que no se reducen a lo ideológico, sino que implican lógicas propias de la reproducción material, traducidas en gastos sociales destinados a garantizar un cierto grado de consenso de las clases dominadas. La contradicción entre ambas funciones genera tensiones y sucesivas crisis cuya resolución depende, precisamente, de la fuerza y aptitud de las clases con intereses confrontados para imponer las soluciones que les sean más favorables (1). Esta dinámica se subordina, en un sentido, a

\footnotetext{
Abogada Universidad de Buenos Aires. Maestría en Ciencias Sociales en FLACSO. Maestría en Administración Pública en la Facultad de Ciencias Económicas de la Universidad de Buenos Aires. Titular de la materia "Crisis y Transformación del Estado Periférico Latinoamericano", en la carrera de Ciencia Política de la Facultad de Ciencias Sociales de la UBA. Miembro del Consejo de Redacción de la revista DOXA (Cuadernos de Ciencias Sociales).

(**) Economista (Universidad de Buenos Aires). Maestría en Administración Pública en la Facultad de Ciencias Económicas de la Universidad de Buenos Aires. Profesor de las Facultades de Ciencias Sociales y Filosofía y Letras de la Universidad de Buenos Aires.

(1) En la obra ya clásica de James O’Connor, La Crisis Fiscal del Estado (Editorial Península, Barcelona, 1981), se plantea la contradicción entre las funciones de acumulación y de legitimación, en tanto que ambas se traducen en demandas para la actividad estatal que aumentan los gastos públicos. Como no siempre están a mano los ingresos necesarios para enfrentar las necesidades creadas, puesto que los frutos de la acumulación no están socializados, se produce la crisis fiscal y las tensiones consecuentes. Ello está relacionado con la lucha de clases, que limita la capacidad del estado para racionalizar al capitalismo. Por eso, la estructura interna del estado resulta ser un producto, un objeto y un determinante del conflicto de clases.
} 
la fuerza y organización de las clases populares para lograr que sus demandas sean satisfechas y, en otro, a la capacidad (voluntad política)-posibilidad (condiciones objetivas estructurales) de las clases dominantes para hacer las concesiones necesarias a efectos de mantener un dominio hegemónico basado sobre el consenso, o para imponer coercitivamente sus condiciones al resto de la sociedad. La articulación de estos factores en las realidades concretas, remite a la dinámica de coerción y consenso y especifica los tipos de dominación (dictadura - hegemonía) y las funciones estatales.

En los países periféricos como el nuestro, el estado tiene otra "tarea" que complejiza las funciones anteriores: construir algún margen de autonomía para sus políticas en el marco de la inserción dependiente del sistema productivo nacional en el mercado mundial, que por otra parte debe asegurar haciendo funcionales sus recursos internos para las lógicas de acumulación del capital a nivel internacional. De este modo, la posibilidad de construir una voluntad nacional a partir del estado, se presenta fuertemente vulnerable a los condicionantes externos (THWAITES REY, 1989).

\section{EL ESTADO-NACION ARGENTINO EN PERSPECTIVA HISTORICA}

Desde su constitución como Estado-Nación a fines del Siglo XIX, la Argentina tuvo la posibilidad de "construir" una lógica de accionar estatal con importantes márgenes de autonomía, a partir de moverse en un marco de holgura fiscal relativamente elevado. La captación de una parte de la renta agraria fue el elemento determinante, sobre todo desde mediados del siglo XX: el desarrollo de una industria destinada al mercado interno, la redistribución progresiva del ingreso, expresada no sólo en salarios sino en todo el sistema de seguridad social garantizado por el estado y en la provisión de servicios públicos a precios relativamente bajos por parte de las empresas estatales, fueron expresiones de ello. Estas tareas, funcionales a los requerimientos del desarrollo "keynesiano" de la burguesía industrial en esta etapa, basado en la ampliación del consumo interno, redundaron en el afianzamiento del papel legitimador del estado y contribuyeron a crear el imaginario "estatalista" hoy en crisis (2). Por supuesto que esta modalidad de intervención estatal no dejó de tener sus tensiones propias y aún sus cuestiones irresueltas. Hasta hace 20 años funcionaba el estado de compromiso nacionalpopular, lo que implicaba un patrón de acumulación basado en la sustitución de importaciones cuyo punto fuerte era la holgura fiscal antes mencionada y cuya debilidad estaba centrada en la vulnerabilidad del sector externo, que ocasionaba recurrentes problemas de balanza de pagos. Por aquella época, la ausencia de un patrón de hegemonía claro impedía armar un proyecto de largo plazo como nación, más allá de las altas tasas de crecimiento económico. Lo no resuelto con relación a la inserción del peronismo en el sistema de poder, y más globalmente la falta de representación orgánica de los actores de un proyecto industrialista, generaba las tensiones sociales que llevaron a la crisis del modelo.

Acá nos permitiremos hacer la interpretación de que lo que en realidad llamamos "crisis", no es más que la manifestación de la ineficiencia dinámica (GERCHUNOFF -GUADAGNI, 1987) de la acumulación en la Argentina. Cuando las distintas variantes de financiamiento del gasto público -vía transferencias de renta agraria- se agotaron, y cuando el esquema regulatorio se tornó disfuncional, se desnudaron las consecuencias de la incapacidad de los capitales individuales argentinos de tornarse competitivos a nivel internacional. Esta ineficiencia dinámica será producto de la particular forma de acumulación de los grupos económicos dominantes, de las presiones privadas sobre el aparato del Estado para crear esos senderos de ineficiencia y de una lógica lobbystica de preservación de los capitales individuales por sobre la eficiencia global.

Pero en 1975 el conflicto asume en primera instancia un carácter político, producto de las irresueltas cuestiones sobre el poder. Es cierto que existía una crisis económica, asi como que intervenía un elemento exógeno novedoso: la recesión producto del derrumbe del modelo fordista, sintetizado en la caída de los precios internacionales del petroleo. Pero la disputa abierta en el terreno de la hegemonía política la amplifica hasta extremos de no retorno.

\section{LA OLA NEOCONSERVADORA}

En el terreno político-ideológico 1976 implica la llegada al poder de un diagnóstico: el de la forma peculiar que asume el pensamiento neoconservador del Cono Sur, que iguala desarrollo a apertura económica internacional irrestricta, identificando las trabas en la mera existencia del Estado. El supuesto básico del esquema neoconservador latinoamericano era la imposibilidad de tornar gobernable el sistema (y por lo tanto promover el siempre postergado desarrollo) con la sobrecarga de demandas sobre el Estado. Desde este enfoque, se produciría un estallido de las cuentas fiscales producto del intervencionismo, tanto en forma directa -productor de bienes y servicios por medio de las empresas públicas- como a través de su rol social como agente redistributivo. En realidad este planteo no es muy novedoso: no es otra cosa que la adaptación subdesarrollada de las propuestas que dieron origen al neoconservadorismo allá a mediados de los setenta con las recomendaciones de la Trilateral Commission -mercantilizar las prestaciones sociales, despolitizar a la sociedad, aliviar al estado de las demandas exageradas volcadas sobre él y llevadas adelante, aunque no con la "pureza" con que se lo intenta aquí, por los gobiernos de Reagan y Tatcher.

(2) La expresión política más característica de esta etapa la constituye el peronismo, que gobernó el pais en el periodo 1945 -1955 y luego entre 1973 y 1976 
La "lectura" latinoamericana tenía también elementos para explicar los problemas de valorización internacional de nuestro capital industrial: ello se debía al proteccionismo excesivo, que evitaba la competencia de productos externos y hacía que los empresarios "cedieran" fácilmente aumentos salariales, que después trasladaban a precios por mecanismos de mark-up. Esto explicaba la alianza "perversa" que había dado lugar al modelo redistributivo del populismo, culpable de la crisis fiscal y, en clave monetarista, del proceso de inflación reptante. Había que disciplinar entonces a la sociedad, y que mejor que los regímenes de la doctrina de la Seguridad Nacional para instaurar la ley del mercado (CASTILLO, 1991).

Se produce así la quiebra definitiva del modelo de acumulación basado sobre la sustitución de importaciones y, consecuentemente, cambian las modalidades de intervención estatal. Se inició un proceso de concentración económica en manos de unos pocos grupos, profundizándose la tendencia a la transnacionalización de la economía. El estado cumplió un papel central en esta etapa, orientando las empresas públicas y su poder de compra para favorecer el crecimiento de ciertos grupos monopólicos a los que subsidió, debilitándolas y restringiendo los recursos destinados a gastos sociales. Asimismo, las empresas públicas fueron utilizadas como instrumentos de una política económica global, fijándoseles tarifas por debajo de los índices de precios como estrategia antiinflacionaria -descapitalizándolas- y sometiéndolas a endeudamiento externo, con el objetivo de regular las tenencias de divisas, operación destinada a favorecer la acumulación de los grupos antes mencionados. A contramano de su prédica liberalprivatista, el estado acudió en ayuda del capital privado, como en los casos de quiebras de entidades financieras o, especialmente, cuando subsidió a los deudores privados al estatizar su deuda externa.

Este cambio en la orientación estatal supuso una renuncia a la función legitimadora en beneficio de la acumulación, sobre la base del recrudecimiento de la coerción. Porque para emprender una transformación tan profunda del papel estatal fue preciso desarticular a los sectores populares, imponiendo el terror dictatorial. El enfrentamiento se resolvió a favor del bloque dominante, que infligió una seria derrota a las clases subalternas, a las que impuso condiciones de disciplinamiento, no solo represivas, sino modificando sustancialmente el carácter de la estructura productiva sobre la que asentaban su capacidad para hacer valer sus demandas.

Durante toda esta época, si bien se desmantela el estado de compromiso nacional popular abriendo paso a un Estado Subsidiador de los grandes grupos económicos, se sigue todavía contando con un margen de holgura fiscal, aunque ya no producto de la apropiación de renta agraria, sino de toma de créditos en el exterior. Es la objetivación más perversa de lo que años antes Fernando Henrique Cardoso (1989) había llamado anillos burocráticos, donde una parte de la sociedad civil pasa a existir dentro del aparato del Estado. En nuestro caso, las instituciones estatales llegan a ser virtualmente colonizadas, dando lugar a un capitalismo asistido y parasitario.

\section{LA LOGICA DEL AJUSTE PERMANENTE}

Este espacio de holgura se acaba en 1982, con la crisis de la deuda. Entramos así en una lógica del ajuste permanente en el marco de una recurrente e irresoluble crisis fiscal. El fin de la holgura fiscal prácticamente coincidió con la vuelta a la democracia y, por lo tanto, con la necesaria resolución no represiva del tema de la legitimación, colocando la cuestión de la crisis, la aceleración inflacionaria y, consecuentemente, la gobernabilidad en una trampa de acero, sobredeterminada por la problemática financiera externa.

El gobierno surgido de las urnas en 1983 siguió un derrotero similar al de sus pares de la región. En una primera etapa, apoyándose en una mezcla de legitimidad ciudadana -vigencia del Estado de Derecho-, y nacional y popular intento de resolución inclusiva de la problemática económica- se avanza con una política "clásica" latinoamericana, chocándose casi inmediatamente con la restricción externa y su correlato financiero interno. En muchos casos la manifestación son agudos procesos inflacionarios que horadan la legitimidad inicial, acompañados de tironeos y disputas con los organismos financieros internacionales. Estos, unidos a los sectores de poder internos, que han modificado su estructura durante los regímenes burocrático autoritarios -cosa no muy bien entendida por los gobiernos democráticos, por lo menos en esta etapa- ponen al desnudo las relaciones de fuerzas existentes .

La crisis de legitimidad entonces planteada, en el caso argentino en 1985, implica una veloz "bajada a la realidad". Es el momento del "ajuste heterodoxo" (Plan Austral), tolerado, pero no necesariamente preferido, por los organismos internacionales. Pero este ajuste, a pesar de lograr algunos triunfos internos de envergadura, especialmente en la faz de la estabilidad de precios, no alcanza para sostener la legitimidad, produciéndose pérdidas de apoyo sobre todo de los sectores más desprotegidos de la sociedad. Los poderes locales, que abogan por un ajuste "ortodoxo" negocian, presionan, y cuando la legitimidad popular del proyecto está lo suficientemente baja, destruyen la opción heterodoxa.

Mientras se desarrollan estos dos momentos, y especialmente durante el ajuste heterodoxo, las tendencias a la transnacionalización de la economía, concentración del poder económico y utilización de los recursos estatales en beneficio de los grandes grupos nacionales y multinacionales continuaron acentuándose. Por otra parte, en la medida en que la reestructuración del mercado mundial ha desdibujado los roles que claramente desempeñaban las economías periféricas como la nuestra en el modelo de acumulación capitalista a escala mundial, parecería que la función estatal de garantizar la inserción en el mercado mundial se limitaría a servir la deuda externa y a brindar oportunidades de negocios a los capitales internacionales. De este modo, al 
asumir el Estado la gravosa carga de pagar los intereses de la deuda, y por lo tanto imponerse la lógica del mercado transnacionalizado, se debilita la autonomía del estadonación para fijar y planificar sus propias políticas económicas.

El paso a la efectivización del ajuste, así asuma características de "heterodoxo", implica la comprobación fáctica por parte de expresiones políticas populistas de que, sin espacios de holgura fiscal, sin una nueva forma de gestión de lo público y con el panorama que ofrece la rejerarquización de la economía mundial, no hay margen para el sostenimiento de las viejas formas de legitimación de lo "Nacional y Popular" en tanto fundamento y referente del Estado 1986). La brutal comprensión de que esas calidades de intervención pública no eran producto de ninguna autonomía del Estado, sino de su funcionalidad con un momento de la acumulación del capital, y más, la verificación de que aún en esos momentos de funcionalidad ello no había bastado para garantizar la puesta en valor del capital argentino a escala internacional (excepción hecha, y no por mucho tiempo más, de la producción primaria de la Pampa Húmeda) son, sin duda, elementos insustituibles en cualquier caracterización seria de la crisis.

En síntesis, a pesar del ajuste permanente se mantienen las políticas subsidiadoras del gran capital, al mismo tiempo que se encuentra una inestable resolución del tema de la legitimación: lo electoral abre por una parte un espacio de legitimación per se, pero por otra lo irresuelto de las demandas sociales genera importantes tensiones hacia la deslegitimación.

\section{LA FRAGIL LEGITIMACION SIN "SOCIALIZACION CAPITALISTA"}

La práctica irreversibilidad del ajuste vuelve a poner sobre el tapete las fuentes de legitimación de las políticas. Y para evitar idealizaciones lo correcto es remitirse a qué implica eso que llamamos la socialización capitalista: la colocación de lo económico en el plano hegemónico de la reproducción social. No hay reproducción social si esta no está garantizada por lo económico: no hay orden ni ingeniería política posible que resuelva lo social si esto no se resuelve desde lo económico. Pensar posibilidades en contrario implica no comprender que es el capitalismo en tanto proyecto social que se funda desde lo económico, en una lógica donde las reproducciones del individuo, de la naturaleza y de la creación de ciencia y tecnología están subordinados a la creación y realización de valor. E1 Capitalismo no permite la reproducción de grupos sociales de envergadura por fuera de lo mercantil, y es una constante batalla por destruir formas de socialización alternativas.

Ahora bien, en los momentos de auge del Welfare State o, en nuestro caso, cuando los márgenes de holgura fiscal hacían compatibles políticas de generalizado acceso a la mercancía con la acumulación del capital, esta temática podía soslayarse. Pero cuando "lo económico" empieza a transformarse en la planta carnívora que devora a velocidades astronómicas legitimidades trabajosamente construidas, la cuestión real adquiere dramática vigencia.

En 1989 hace quiebra este modelo, tornándose ahora insostenible la coexistencia de la crisis fiscal con el estado subsidiador. La trágica manifestación de esta incompatibilidad es la retirada desordenada del estado en todos sus términos, aún en aquellos que hacen a su esencialidad en los planteos más clásicos (justicia, administración, monopolio de la fuerza, curso forzoso de la moneda, etc.) La materialización de esa quiebra se da a partir de explosiones hiperinflacionarias, que nos obligará a incorporar una serie de elementos fundamentales para comprender las fuentes de legitimación de los regímenes que sucedieron a estos procesos.

Excedería el propósito de este trabajo hacer una teorización de los efectos de las hiperinflaciones sobre los sectores populares, aunque creemos que es una tarea pendiente impostergable. Digamos solamente que los procesos hiperinflacionarios suponen una interpelación en tanto que productores y consumidores individuales: se genera una lógica hobbesiana donde los mensajes se asimilan más desde el sujeto del neoconservadorismo que participa de la lucha mercantil por la supervivencia del más apto, que desde la integración comunitaria y la solidaridad. Se produce asi un descenso de expectativas y se abren entonces espacios para la legitimación no ya por el fetichismo de la mercancía, ni tampoco por lo tradicional no mercantil, sino en términos de eficacia. Un régimen político estará legitimado, entonces, si es capaz de exorcizar a los "fantasmas de la desestabilización". Ya no importará que exista en la intervención estatal una "apariencia de neutralidad", que sea "nacional y popular" o excluyente, porque no es juzgado por ello. Poco importa que sea lo que parece no ser, con tal de que sea eficaz. La legitimidad del Estado parecería fundarse, entonces, en la garantía de estabilidad económica como valor en si mismo, mas allá de la posibilidad efectiva de consumo.

En este punto, cabría preguntarse si no estamos ante una nueva reificación, y que el mediano plazo demostrará que detrás de esta legitimación por la eficacia podría reaparecer la más clásica cuestión del acceso generalizado a la mercancía. Y probablemente la incapacidad de solucionarla volverá a conducir a déficits de legitimación ya que la otra cara de la moneda es la virtual retirada del estado, la fragmentación social, un acelerado dualismo societal, una cada vez mayor incapacidad de las instituciones estatales para enfrentar y resolver problemas, el deterioro de la integración simbólica tanto de prácticas políticas como sociales o culturales. En síntesis, un avance hacia un comportamiento anómico de la legitimación, con una prevalecencia de altos contenidos de violencia no necesariamente estatales. 


\section{LA REFORMA ESTATAL EN LOS NOVENTA}

Este es el marco estructural en el cual el 18 de agosto de 1989, a poco más de un mes de la asunción del gobierno justicialista del Dr.Carlos Menem, fue promulgada la ley $\mathrm{N}^{\mathrm{o}}$ 23.696, conocida como de Reforma del Estado. En un trámite ajetreado, que ocasionó sucesivos tironeos entre ambas cámaras y que demoró la sanción más allá de los deseos y urgencias del Poder Ejecutivo, finalmente, y en el plazo "record" de veinte días, se dio a luz una ley que constituye y consagra- un viraje fundamental respecto al papel que el Estado argentino desempeñara en los cincuenta años anteriores.

La reforma del Estado, en clave de achicamiento de su tamaño global -racionalización- y privatización de empresas públicas había entrado naturalmente en la agenda gubernamental del gobierno de Alfonsín en la etapa en que se asume el ajuste heterodoxo. Más allá de la privatización de algunas empresas del área de defensa y de planes de explotación petrolera que suponían privatizaciones virtuales, ya en 1988 el gobierno impulsa, de la mano de su flamante ministro de Obras y Servicios Públicos, Rodolfo Terragno, ambiciosos proyectos de asociación con capitales extranjeros de dos empresas estatales claves: Aerolíneas Argentinas y la Empresa Nacional de Telecomunicaciones (ENTEL). Estos proyectos, que partían del reconocimiento de la carencia de recursos para hacer frente a las inversiones que ambas empresas requerían, como consecuencia de la crisis fiscal que atravesaba el Estado argentino, fueron tenazmente resistidos por la oposición peronista e incluso por amplios sectores del gobernante partido radical. La crisis económico-social que precipitó la derrota electoral del radicalismo y el apresurado traspaso del gobierno, dejaron sin concreción los más significativos proyectos privatizadores conocidos.

Pero, paradojalmente, esa misma crisis sirvió de fundamento para que el Presidente Carlos Menem, ungido por el voto de quienes se oponían a los planes privatistas del gobierno anterior, no sólo pusiera en práctica un drástico programa de ajuste económico ahora si de corte ya netamente ortodoxo, sino que asumiera como propio el diagnóstico de la crisis que el neoconservadorismo latinoamericano venía esbozando desde casi veinte años atrás. Así, en medio de una cruzada antiestatista se inició un camino en el que las privatizaciones aparecieron como un pilar esencial de la reformulación global de la relación sociedadestado.

Cuando se hace referencia a la "Reforma del Estado", en realidad se trata de una serie de procesos que remiten a transformaciones profundas en las estructuras económicas, sociales y políticas y su articulación. La política de privatizaciones es una parte sustantiva de ellas, pero no las resume. Porque también se incluyen distintas facetas que, aunque estrechamente relacionadas por ser partes de un proceso global que tiene lugar de manera sucesiva y/o simultánea, deben ser diferenciadas a los efectos de posibilitar el análisis de los rasgos característicos de cada una de ellas. Estas facetas comprenden también lo relativo a la reorganización y ajuste de la administración central y las provinciales, lo atinente a la reestructuración de las relaciones capital-trabajo, conocida como "flexibilización laboral" y lo referido a las transformaciones en la estructura tributaria, entre otras.

\section{LAS PRIVATIZACIONES DEL ENTEL Y AEROLINEAS ARGENTINAS}

Si bien el espectro a privatizar era bastante amplio, el gobierno inicialmente concentró sus energías en impulsar la venta de algunas áreas claves . Y acá correspondería señalar los objetivos explícitos e implícitos: en cuanto a los primeros aparece la necesidad de reducir el déficit fiscal y de hacerse de recursos frescos para pagar los compromisos externos, unido a la posibilidad de ofrecer activos públicos en la operatoria de capitalización de la deuda. Pero lo más importante se encontraba en el objetivo implícito: enviar señales claras hacia el exterior y el interior de la sociedad argentina sobre la firmeza del nuevo rumbo que emprendía el gobierno. Hacía los Estados Unidos, se planteaba un cambio en la política exterior que incluía un alineamiento incondicional con el país del Norte y la búsqueda de renegociación financiera externa en el marco de esta lógica; hacia los inversores privados externos e internos, se exhibía una clara voluntad privatista y pro-negocios, capaz de llevar tranquilidad y atraer las posibles inversiones; y hacia el sindicalismo nativo se exponía la firmeza y decisión de hacer cumplir a rajatablas, y contra toda resistencia, el nuevo rumbo asumido por el gobierno, a contramano de la tradición histórica del peronismo en materia estatal.

De ahi que se decidiera comenzar por privatizar dos empresas que, además de resultar relativamente fáciles de vender en el mercado internacional por sus altas tasas de rentabilidad, se constituían en casos "testigos" de alto valor simbólico por su significación social: ENTEL y Aerolíneas Argentinas.

La empresa de teléfonos (ENTEL) resulta el caso más típico, ya que se trata de una empresa de servicios especialmente importante para los sectores medios y altos de la población, capaces de modelar la "media" universalizable de la "opinión pública". Sobre una larga historia de servicios deficitarios, que llevaba, por otra parte, al continuo enfrentamiento entre el usuario y el empleado estatal telefónico -estigmatizado como el causante de la ineficienciapudo fácilmente no sólo montarse la "solución privatista" como valor indiscutible y único, sino el andamiaje social de apoyo a la ofensiva gubernamental contra la previsible resistencia sindical. Porque en este sentido, la derrota y disciplinamiento de un gremio estatal fuerte y bien organizado también era un objetivo clave en esta primera etapa. 
El caso de Aerolíneas también resultaba importante, ya que al ser una aerolínea de bandera, afectaba el sentimiento de "soberanía nacional" enraizado en partidos, sindicatos y gran parte de la historia política argentina. Pero a diferencia de ENTEL, los servicios de aerotransporte son utilizados por franjas reducidas de la población, de ingresos altos, y la calidad de los prestados por Aerolíneas nunca había sido seriamente cuestionada, ya que lo hacía de manera relativamente eficiente. Aquí la cuestión pasaba por el elevado volumen de endeudamiento externo de la empresa, heredado de la gestión militar que la había utilizado como herramienta de política macroeconómica, que no tenia relación con lo estrictamente operativo donde era superavitaria-, pero que significaba un continuo drenaje fiscal. A ello se le sumaba la anunciada desregulación del mercado aéreo internacional para 1992, que colocaba en peligro a las pequeñas empresas de bandera, argumento principalmente expuesto como fundamento de la necesidad de privatizar, para aportar los capitales necesarios.

Más que a criterios de oportunidad y conveniencia valorados con racionalidad técnica y/o económica "puras", en los casos de estas empresas el gobierno actuó urgido por demostrar su voluntad política de producir transformaciones sustanciales. De ahí que la elaboración de los pliegos de licitación y la conducción de los procesos de privatización se llevara adelante en función de cronogramas explícitos y poco flexibles. Esto que de por si restaba márgenes de maniobra al vendedor frente a los posibles compradores, permitiéndoles especular con su urgencia, se combinó con la saturación mundial de la oferta de empresas de las mismas ramas ofrecidas por otros países deudores, tornando aún más vulnerable la posición argentina en términos de conveniencia económica.

Fue asi que ENTEL, dividida en dos, fue adjudicada a sendos consorcios integrados por operadores internacionales, bancos tenedores de títulos de deuda pública y grupos locales: la Telefónica de España y TELECOM, una asociación de capitales principalmente franceses e italianos.

La privatización de Aerolíneas resultó mucho más azarosa, con idas y venidas desde la confección misma de los pliegos, y con el retiro de la mayoría de los eventuales interesados antes de la presentación de la oferta. De tal modo, la empresa fue adjudicada al único oferente, un consorcio liderado por Iberia e integrado, entre otros, por Cielos del Sur, la empresa que desde 1987 opera la aerolínea de cabotaje local Austral, constituyendo de este modo un monopolio en los vuelos nacionales. Si bien la transferencia de la empresa se realizó hacia fines de 1990, la situación jurídica y económica continúa siendo discutida, ya que los adjudicatarios no concluyeron aún los pagos y no han cumplido acabadamente con lo estipulado en los pliegos de la licitación.

Cabe señalar que, hasta el presente, en ambos procesos de privatización no se verificaron las inversiones pactadas en los pliegos de licitación y contratos de transferencia, necesarias para mejorar el funcionamiento de las empresas. En el caso de ENTEL, y pese a las considerables ganancias reconocidas por las propias adjudicatarias, se está muy lejos aún de producir las inversiones necesarias para mejorar significativamente la prestación de los servicios, que continúan siendo sumamente deficitarios. En el caso de Aerolineas Argentinas S.A., a las discusiones con el gobierno en torno a la incorporación pactada de nuevos aviones -aún no concretada-, se le suma el deterioro en la calidad de los servicios (3) denunciado por usuarios y trabajadores aeronáuticos.

Por tales razones suelen plantearse estos casos de privatización, aún en ámbitos gubernamentales o próximos al oficialismo, como los claros ejemplos de como no deben llevarse adelante las futuras privatizaciones.

\section{LA PRIVATIZACION DEL SECTOR TRANSPORTE-COMUNICACIONES}

Paralelamente a estos dos casos "piloto", desde fines de 1989 el gobierno dictó diversos decretos-marco para la privatización de otras empresas y actividades que comenzaron a seguir sus propios procesos. Tal es el caso de Ferrocarriles Argentinos, que de por si plantea innumerables dificultades por las características estructuralmente deficitarias del sector en casi todas partes del mundo. Aquí se comenzó por intentar la privatización de los "corredores" más rentables, es decir los ramales que unen puntos de alto movimiento económico, como el tramo Rosario-Bahía Blanca, que surca la región agrícola más rica de la Argentina, por lo que en él tienen intereses las más importantes empresas cerealeras que operan en el país. Este proceso aún no fue concluido y ha presentado innumerables avatares.

Párrafo aparte merecen las líneas suburbanas que unen la Capital Federal con el Gran Buenos Aires y alrededores, de gran densidad de público usuario -de bajos recursos-, pero poco rentables. Descartada la posibilidad de clausurarlas como estuvo tentado a hacer el gobierno en más de una oportunidad, para enfrentar drásticamente las rebeldías de los trabajadores ferroviarios afectados por el incesante decrecimiento de sus salarios-, por el descalabro macroeconómico y social que produciría, el gobierno negocia ahora la confección de pliegos licitatorios para los distintos ramales, que premien la menor demanda de subsidio estatal para operarlos. Obviamente, el objetivo de estas privatizaciones apunta más a reducir un poco el déficit fiscal que aumentar la recaudación fiscal para hacer frente a la deuda externa, a la par que se exhibe el relativo interés de un Estado asentado sobre un modelo de acumulación concentrado y expulsor de hacerse cargo del "costo" de colocar en sus lugares de trabajo a la mano de obra necesaria para los capitalistas individuales. De algún modo se está cuestionando el papel del Estado como "capitalista colectivo ideal".

(3) El caso del contagio de cólera de varios pasajeros y tripulantes por la ingesta de alimentos contaminados en un vuelo Buenos Aires-Miami, con escala en Lima, que tuvo lugar en el pasado mes de enero, es solo el ejemplo más patético. 
La concesión por peaje de la explotación y mantenimiento de las rutas argentinas pareciera dirigirse a satisfacer las demandas de algunos grupos locales anteriormente beneficiarios del modelo de Estado Subsidiador, en su carácter de contratistas del Estado, a modo casi de "premio consuelo" que, simultáneamente, procura su adhesión al modelo global. En tal sentido se han adjudicado miles de kilómetros de rutas ya terminadas, autorizándose el cobro de peaje aún antes de haberse efectuado cualquier mejora significativa, lo que resulta un negocio sumamente ventajoso que elimina el riesgo empresario sin proveer, simultáneamente, beneficios palpables para los usuarios. No obstante, debió ser ajustado respecto a sus planteos originales debido a las fuertes -y previsibles- resistencias que generó en distintos sectores afectados y el público usuario en general.

\section{LA PRIVATIZACION DE UN SECTOR CLAVE: EL ENERGÉTICO}

Promediando 1991 comenzó a plantearse firmemente la privatización de un sector clave para la economía en su conjunto: el energético. Así, comenzaron a discutirse los marcos regulatorios de los servicios eléctricos y la enajenación de las centrales generadoras, por una parte, y el esquema de privatización de la red gasífera actualmente operada íntegramente por el Estado.

Ambos sectores son especialmente significativos en la medida en que tienen un fuerte impacto macro y microeconomico. Es fácil advertir entonces la magnitud de intereses en juego a la hora de definir el destino de sectores sustantivos en la configuración de costos de la mayoría de las industrias. La discusión parlamentaria de los marcos regulatorios de ambas actividades puso en evidencia las diferencias en las lógicas que se ponen en juego en cada privatización. Por un lado, el gobierno se encuentra atenazado por los compromisos que contrató con la banca acreedora y debe, por tanto, hacerse de la mayor cantidad de recursos posible para saldarlos. En este sentido, debería ofrecer mejores tarifas a los posibles interesados, para de este modo aumentar tanto la cantidad como la calidad de las las ofertas, obteniendo así mayores recursos fiscales. Pero esto significa encarecer servicios que impactan directamente sobre el costo de vida, por lo que podrían desatar procesos inflacionarios que trabajosamente el plan de estabilidad del actual Ministro de Economía, Domingo Cavallo, ha logrado frenar. Se desprende que la ecuación planteada es muy compleja, y en ella se articulan los distintos intereses en juego, internos y externos, mediatos e inmediatos.

\section{BREVE CONCLUSION PROVISORIA}

Podemos concluir que el proceso privatizador impulsado por el actual gobierno argentino abre, al menos, dos órdenes de interrogantes. Por una parte, en el plano estrictamente económico se plantea la pregunta de qué sucederá cuando las cuentas fiscales ya no puedan ser cerradas con lo producido por las privatizaciones -como viene pasando actualmente-, en la medida que se refieren a bienes necesariamente agotables. La reforma tributaria que impulsa el gobierno parecería apuntar a obtener recursos más genuinos y estables, y que no sean sólo los sectores de ingresos magros y fijos -la mayoría de la población los que tributen por la vía de los ineludibles e indiscriminados impuestos al consumo, sino que efectivamente comiencen a pagar -nuevo "pacto fiscal" mediante- aquellos sectores económicamente poderosos que tradicionalmente eludieron hacerlo en una magnitud como en pocos lugares del planeta. Y ello no por razones ideológicas o de justicia social, sino porque la tributación de los sectores populares únicamente ya no era suficiente para hacer frente a los compromisos contraidos e intentar consolidar el modelo en curso.

Por otra parte, pareciera que la expectativas centradas en el proceso privatizador como "mito fundante" y panacea universal, para ser mantenidas en tanto que efecto legitimador deben, en algún momento, ser corroboradas en la experiencia concreta de mejores servicios para la mayoría de la población. De lo contrario, no es difícil imaginar como la frustración operará en sentido opuesto, deslegitimante.

En tanto que proceso inacabado, no es posible aún sacar conclusiones definitivas sobre las transformaciones que se están operando en el Estado argentino. sólo nos aparecen muchas dudas en torno a los beneficios efectivos que las mismas podrían deparar para la mayoría de la población, luego de dolorosas décadas de privaciones, en el incierto y próximo siglo.

\section{REFERENCIAS BIBLIOGRAFICAS}

*CARDOSO, Fernando Henrique, (1989): Imperialismo y dependencia en la América Latina, en ECONOMIA INTERNACIONAL, René Villarreal comp., El Trimestre Económico $\mathrm{N}^{\mathrm{o}} 30$, México.

*CASTILLO, José, (1991): Crisis de la legitimidad de lo público, en REALIDAD ECONOMICA Nro. 98, Buenos Aires.

*DESPERBASQUES, Mónica y CASTILLO, José, (1991a) Estado y proyectos populares, en DOXA Nro.6, Buenos Aires.

*DOS SANTOS, Mario y CALDERON, Fernando, (1990): Hacia un nuevo orden estatal en América Latina, PNUD-UNESCO-CLACSO.

*GERCHUNOFF, Pablo y GUADAGNI, Alieto, (1987): Elementos para un programa de reformulación económica del Estado, Mimeo.

*MATHIAS, Gilberto y SALAMA Pierre, (1986) El Estado sobredesarrollado, Era, México. 
*O'DONNELL, Guillermo, (1986): Apuntes para una teoría del Estado, en OSZLAK, Oscar (comp.) TEORIA DE LA BUROCRACIA ESTATAL, Paidos, Buenos Aires.

*THWAITES REY, Mabel, (1989) ¿El fin de los espacios estatales nacionales?, en REALIDAD ECONOMICA $\mathrm{N}^{\circ} 90,5$ to.bimestre, Buenos Aires.
*THWAITES REY, Mabel, (1990a) Auge y ocaso de la intervención estatal o la difícil legitimación de la ley de la selva, en DOXA $\mathrm{N}^{\circ} 2$, Buenos Aires.

*THWAITES REY, Mabel y LOPEZ, Andrea (1990b) México y Argentina: modernización capitalista y reforma del Estado, en REALIDAD ECONOMICA $\mathrm{N}^{\circ} 96$, 5to.bimestre, Buenos Aires.

\section{RESUMEN}

Los Autores tratan de analizar el caso de la reforma del Estado en la Argentina, que ha tomado la forma fundamentalmente, de un proceso brutal de privatización. Los autores llevan a cabo este análisis tomando la Reforma del Estado como un proceso global, enmarcada tanto dentro del contexto internacional como del político interno referente a la transición, del estado como un proceso global, que abarca a toda la lógica del funcionamiento de lo público y que por tanto, no es efecto sólo de una decisión adoptada por el gobierno de Menem.

ABSTRACT
The authors analyze the State Reform in Argentina, characterized by a great privatization process. From a global pers-
pective, considering external and internal political factors such as the transition or the new technological changes in the
world, the State Reform includes a whole logic of public functioning, not only an effect of a decission taken by Menem
government.

